Article

\title{
Socio-Economic Viability of Urban Agriculture-A Comparative Analysis of Success Factors in Germany
}

\author{
Thomas Krikser ${ }^{1, *}$, Ingo Zasada ${ }^{2}$ and Annette Piorr ${ }^{2}$ (D) \\ 1 Department of Agricultural and Food Marketing, Faculty of Organic Agricultural Sciences, \\ University of Kassel, 37213 Witzenhausen, Germany \\ 2 Leibniz Centre for Agricultural Landscape Research (ZALF), 15374 Müncheberg, Germany; \\ ingo.zasada@zalf.de (I.Z.); apiorr@zalf.de (A.P.) \\ * Correspondence: t.krikser@uni-kassel.de
}

Received: 5 March 2019; Accepted: 29 March 2019; Published: 4 April 2019

\begin{abstract}
Socio-economic viability of urban agriculture (UA) is, especially regarding non-commercially oriented initiatives, at most a generically treated issue in scientific literature. Given a lack of data on yields, labor input, or saved expenditures, only a few studies have described it either from a cost-avoidance or a specific benefit generation perspective. Our hypothesis is that hybrid roles of consumers and producers in urban agriculture challenge the appraisal of socio-economic viability. This paper presents an empirical study from three prevalent urban agriculture models: self-harvesting gardens, intercultural gardens, and community gardens, combining qualitative and quantitative survey data. A multi-value qualitative comparative analysis was applied to grasp the perception of socio-economic viability and its success factors. This allowed us to identify necessary and sufficient conditions for economic and social success. Results give an indication of the existence of different value systems and cost-benefit considerations in different urban agriculture models. A service-focused business relationship between farmers and consumers ensuring self-reliance is important for success for self-harvesting gardens, while self-reliance and sharing components are relevant for intercultural gardens. Community gardening builds upon self-governance ambitions and a rather individually determined success and failure factor pattern beyond explicit production output orientation. It is shown here for the first time with a quantitative approach that participants of urban agriculture models seem to go beyond traditional trade-off considerations and rather adopt a post-productive perception, focusing more on benefits than costs.
\end{abstract}

Keywords: urban agriculture; qualitative comparative analysis; community gardens; self-harvestinggardens; intercultural gardens; cost-benefit considerations

\section{Introduction}

A number of agricultural concepts under the umbrella of "alternative food networks" [1] have been particularly observed in urban and peri-urban contexts of the Global North in recent years [2-4]. Examples comprise urban gardening initiatives, including intercultural (ICGs) and community gardens (CGs) [5,6]; new forms of consumer-farmer initiatives also encompassing the peri-urban areas [7], such as self-harvesting or rental gardens [8]; and Community Supported Agriculture (CSA) [9,10].

Within an ongoing debate about the advantages and drawbacks of urban agriculture (UA) [11], most publications point out the multiple individual and public benefits. The latter refer to food security [7], environmental resilience, justice [12], social capital, trust, transparency [13], social inclusion and participation, especially in distressed neighbourhoods [12,14], capacity building, health, and educational issues [7]. With the acknowledgement of benefits for various sectors, such as health, 
education, local economy, quality of life, and social issues, UA is increasingly interesting and relevant for urban policy and food system planning $[2,15]$.

The Food and Agricultural Organization of the United Nations [16] clearly points out that the sustainability of urban and peri-urban farming models "[ ... ] implies its ability to continue in the future (and therefore) should be profitable and economically viable". Indeed, the economic viability of professional agriculture in an urban context has been discussed mainly from a peri-urban and urban fringe agriculture perspective [17], referring to the strategies of increasing competitiveness utilizing new market opportunities through direct marketing, innovation, and interaction with customers, enabling farmers to meet changing demands and market conditions better [18], as well as contributing to higher economic robustness and, hence, reducing dependency on public support [19]. However, the economic dimension of sustainability, if at all, is described mostly in very generic terms with scarce empirical evidence on the economic viability [20,21].

This individual business perspective obviously differs markedly from the public perspective that focuses mostly on secondary or indirect public economic benefits, for example, the potential of continuous productive urban landscapes to improve the social and economic performance of cities, for instance, through nature-based solutions for climate change adaptation [22]. Therefore, it is suggested that social benefits should also be considered in the cost-benefit assessments [23].

In this context, it seems advisable to differentiate types of UA models according to their social and economic benefits as well as the degree to which these UA concepts are more self-reliant or sharing purpose-oriented. "Self-reliance", as a specific economic benefit dimension, is linked to economic stability, autonomy, resilience, job creation, increased property values, and social empowerment [20] but not cash flows. "Sharing" of resources [24] or values [25] represents another dimension for which UA can be clearly distinguished. This is, for instance, the case in self-harvesting gardens (SHGs) or CSAs with strong consumer-producer interaction based on the sharing of resources and labor. Furthermore, the environmental dimension of sustainability is clearly highlighted by different authors who point out that UA has positive effects on pollination [26], increasing biodiversity, micro-climate regulation, and increased resource-efficiency [27].

Nevertheless, little is known about the question whether these authors define economic viability in a narrow sense, which includes the generation of added value [28], or as an additional contribution to farm income [8]. Subsequently, Krikser et al. [3] have distinguished business, self-supply, and societal models based on their benefit purposes. Among the rare empirical studies providing quantitative data on the economic performance of different UA types, Glavan et al. [21] also distinguish between production for self-supply and for sale by applying two different modeling approaches. They showed an under-exploitation of economic potentials for the non-economic UA types.

Based on the research discussed previously, there is a research gap concerning factors of success for urban agricultural initiatives. To fill this gap, the following research question was derived: how does "non-commercially guided motivation" relate to expectations and concepts associated with economic and social success? For this purpose, the aim is to identify the necessary and sufficient conditions for economic and social viability and success of different non-professional types of UA by applying a multi-value qualitative comparative analysis (mvQCA). Our hypothesis is that criteria for economic success differ between UA types, which indicates that participants' assessment of economic performance is influenced by distinct value concepts that can be contextualized through post-productivism and sharing theories. The empirical work focuses on the three most common UA types in Germany: SHGs, CGs, and intercultural gardens (ICGs). Germany can be seen as a typical European country where UA is far more than the production of food [29]. Lohrberg et al. [30] report that the metalevel benefits in the European Union are more important than the pure production. 


\section{Materials and Methods}

In this section, potential success factors are identified, and the survey, sampling, data collection, method chosen, and mvQCA will be introduced. Section 3 presents the results and discusses the findings. Section four draws conclusions about the novelty, added value, and limitations of the study.

\subsection{Economic Success Factors}

Cost-benefit considerations of different types of UA were taken as a starting point for our investigations on economic viability. Due to the large evidence gap, we are particularly interested in learning more about the secondary commercially oriented types of UA, i.e., rather self-reliance-oriented UA (e.g., ICGs), community-oriented UA (e.g., CGs), and transition forms with commercial orientations (e.g., SHGs). A highly complex set-up of cost and benefit components were assumed for these types. Insights into participants' perception of success factors of socio-economic viability will allow us to identify similarities or differences in their trade-off considerations and background values.

Relevant cost factors in UA are rental payments, fees for participation, labor, and production costs. Cost-sharing practices are reported in literature, for example, CGs sharing space, water, and tools [7]. Relevant benefits are income from sales of surpluses and processing, and self-employment [16]. Literature refers to savings due to less household expenditure on food as a common feature of all UA types [21], while income from sales is related more to professional forms but also to self-harvesting initiatives [7]. However, Dimitri et al. showed that urban farmers, independent of the UA type, are hardly able to generate sufficient income for themselves from their agricultural activity [31]. Further benefits are the exchange of agricultural products for other economic goods [16], savings on health expenditure, education and new knowledge acquired through informal exchange or formalized workshops, and participation and social inclusion.

In addition to the cost and benefit factors listed, existing knowledge points to further factors that determine economic success: experience, level of education, participation, cooperation, and spatial proximity. It is known from professional farming that the level of experience and professionalism is related to the willingness to acquire new knowledge and to the willingness to pay for it. Previous experience and continuous training belong to the key success factors for agricultural cooperatives, for example, marketing [32], and existing knowledge affects the willingness to pay for training and community action positively [33]. Budak et al. [34] report that producers for livestock systems in Turkey who live far away from the extension service showed a higher willingness to pay than those near to it.

\subsection{Survey, Sampling, and Data Collection}

An online survey to collect data was used to answer the research question and find out more about social and economic success factors in UA. The target population of the survey was the existing UA initiatives in Germany listed in the database stadtacker.net (www.stadtacker.net, meanwhile, accessible via www.gruenanteil.net). The database collects experts, networks, articles, and initiatives in the field of UA. All initiatives in the survey that were part of the subcategory "Fields and Gardens" were exported. Initiatives that no longer exist and repeated e-mail addresses were excluded. After this revision, 210 of 318 initiatives were invited to join the survey. The initiatives were invited by a personalized mail with individual access-coded entry which prohibited multiple participation. A reminder to all initiatives that had not yet joined the survey was sent after three weeks. The response rate of $34.3 \%$ (72) for complete datasets was satisfying. The cooperation rate, which includes all initiatives that at least opened the survey, was $46.7 \%$ (98).

The dataset received contains 72 initiatives. Within these cases, three main groups: CGs $(\mathrm{N}=26$, $36.1 \%)$, ICGs $(\mathrm{N}=21,29.2 \%)$, and SHGs $(\mathrm{N}=13,18.1 \%)$ have been identified. Configurational variables were used based on the literature discussed previously to apply a mvQCA [35]. Regarding analysing the success, the criteria for success was distinguished according to the type of UA initiative. According 
to Krikser et al. [3], economic and self-reliance are important outcomes for the initiator (economic) and the participants (self-reliance) of SHGs, and the percentage of participation was used as an indicator for social success for CGs and ICGs. Table 1 indicates the outcomes and configurations that were used to identify sufficient and necessary conditions.

Table 1. Variables for the outcome and configuration of the mvQCA.

\begin{tabular}{cccc}
\hline Type & Variable & Definition & Source \\
\hline \multirow{5}{*}{ Outcome } & $\begin{array}{c}\text { Economic Success } \\
\text { Participation }\end{array}$ & $\begin{array}{c}(0) \text { No regular income for provider; (1) regular income for provider } \\
(0)<50 \% \text { regularly participate; }(1)>50 \% \text { regularly participate }\end{array}$ & {$[3]$} \\
& Self-reliance & $(0)$ No self-reliance during season; (1) self-reliance during season & {$[3]$} \\
\hline \multirow{5}{*}{ Configuration } & Fee & (0) No fee; (1) medium fee $<€ 100$ p.a.; (2) high fee $>€ 100$ p.a. & {$[7]$} \\
& Self-reliance & (0) No self-reliance during season; (1) self-reliance during season & {$[3]$} \\
& Experience & (0) No experience; (1) some experience; (2) high experience & {$[32]$} \\
& Distance & (0) No educational offerings; (1) additional educational offerings & {$[33]$} \\
& Self-organization & (0) Short distance; (1) medium distance; (2) long distance & {$[34]$} \\
\hline
\end{tabular}

\section{Results and Discussion}

This section is divided by subheadings. It should provide a concise and precise description of the experimental results, their interpretation, and the experimental conclusions that can be drawn.

\subsection{Descriptive Analysis}

The most common initiatives in the survey are CGs, with about $36 \%$ of the sample, followed by ICGs $(\sim 30 \%)$, SHGs $(\sim 18 \%)$ and others, including school gardens, beekeepers, and CSAs ( 17\%). These results are comparable with the data of the whole population, where it can be seen that CGs and ICGs represent about two-thirds of all projects in the database. By comparing the three main initiatives, significant differences can be seen in some characteristics and similarities in others (Figure 1). There are three main differentiations between SHGs, on the one hand, and ICGs and CGs, on the other hand: (1) there was a significant association between the type of initiative and whether a regular income is achieved for the provider: $\chi^{2}(2)=8.823, p=0.012$. (2) The participants have a significantly higher chance of covering their demand for vegetables and herbs during seasons in SHGs: $\chi^{2}(2)=10.066$, $p=0.007$. (3) SHGs are more independent of external sponsorship: $\chi^{2}(2)=7.645, p=0.022$.

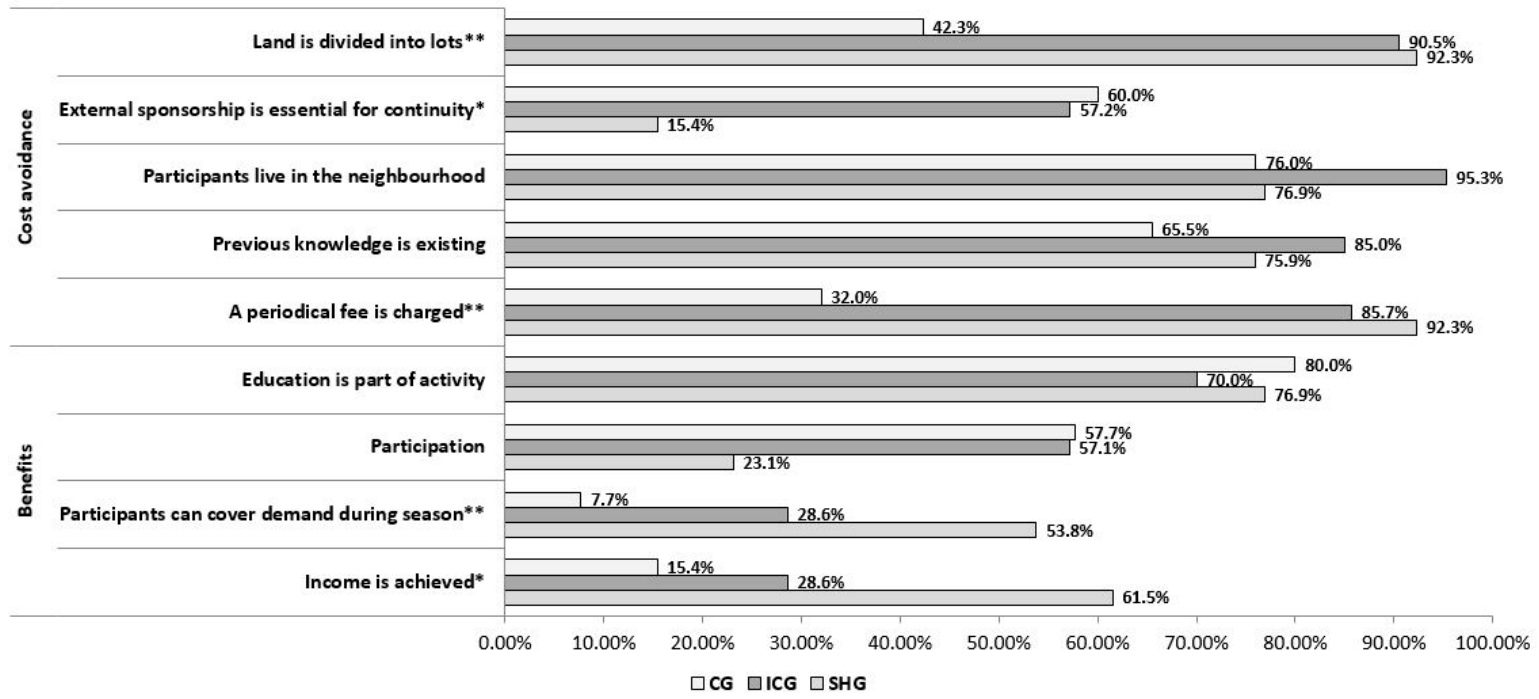

Figure 1. Percentage of fulfilment of various issues for different types of UA. CG: Community gardens; ICG: Intercultural gardens; SHG: Self-harvesting gardens. ${ }^{*}$ Significant at the 0.05 level. ${ }^{* *}$ Significant at the 0.01 level. 
Furthermore, two criteria where CGs differ from ICGs and SHGs could be identified: (1) the chance that participants of a CG pay no fee is significantly higher than in the other initiatives: $\chi^{2}(2)=$ 20.026, $p<0.001$. (2) The odds that CGs are separated into lots is significantly lower than in SHGs or ICGs: $\chi^{2}(2)=16.768, p<0.001$. There were no significant differences between previous knowledge, the distance the participants came from, and the role of education within the initiatives.

It can be seen when comparing the social backgrounds (Table 2) of the main types of UA based on Kruskal-Wallis tests that the age of the oldest participant and the share of women are not affected by the type of UA initiative. Nevertheless, the tests show that the range of persons that participate in an initiative is significantly affected by the type of initiative: $\mathrm{H}(2)=18.757, p<0.001$. Pairwise comparisons with adjusted $p$-values showed that there was no significant difference between the range in ICGs and CGs ( $p=0.213, r=0.26)$ but significant differences between SHGs and ICGs $(p=0.023, r=0.46)$ and SHGs and CGs $(p<0.001, r=0.67)$. Similar results occur for the average fee the participants pay for one year. The fee is also significantly affected by the type of initiative: $\mathrm{H}(2)=$ $22.175, p<0.001$. The pairwise comparisons show no significant difference between ICGs and CGs $(p=1, r=0.01)$, but significant differences between SHGs and ICGs $(p<0.001, r=0.75)$ and SHGs and CGs $(p=0.001, r=0.59)$.

Table 2. Mean scores regarding various attributes for different types of UA.

\begin{tabular}{lllll}
\hline & SHG & IG & CG & Average \\
\hline Range (in persons) & $373.7_{\mathrm{ab}}$ & $59.7_{\mathrm{a}}$ & $50.0_{\mathrm{b}}$ & 123.5 \\
Migration background (in \%) & $10.0_{\mathrm{a}}$ & $65.7_{\mathrm{ab}}$ & $16.3_{\mathrm{b}}$ & 32.0 \\
Average fee (per annum) & $142.0_{\mathrm{ab}}$ & $34.1_{\mathrm{a}}$ & $30.0_{\mathrm{b}}$ & 67.3 \\
Oldest participant (in years) & 72.2 & 72.5 & 66.9 & 70.0 \\
Share of women (in \%) & 63.9 & 64.1 & 62.7 & 63.4 \\
\hline
\end{tabular}

SHG: self-harvesting gardens; IG: intercultural gardens; CG: community gardens. Means in a row sharing subscripts are significantly different from each other. We noted in table that means sharing subscripts are significantly different from each other. The notation $\mathrm{a}_{\mathrm{a}}$ and $_{\mathrm{b}}$ is based on APA standards.

In addition, the Kruskal-Wallis test shows that the share of people with a migration background is also affected by the type of UA initiative: $\mathrm{H}(2)=30.548, p<0.001$. Pairwise comparisons showed that there were no significant differences between SHGs and CGs $(p=1, r=0.08)$ but significant differences between ICGs and SHGs $(p<0.001, r=0.77)$ and ICGs and CGs $(p<0.001, r=0.72)$.

The descriptive statistics of the sample confirmed the correctness of the assumptions made based on existing theory that SHGs are oriented more towards the generation of income and self-reliance, while ICGs and CGs show pronounced features, such as participation in decision processes and a neighborhood component, that are not observe frequently in SHGs. Nevertheless, all types of UA that were examined in this study have common attributes, such as interests, motives, and the composition of participants, and deal with their products in a non-commercial way. Accordingly, they have been previously differentiated according to their focus [3]: SHGs with self-supply and commercial orientation, ICGs with a self-supply and socio-cultural, non-commercial orientation, and CGs with a socio-cultural orientation. The empirical verification of these features in this study allowed us to set the configurations to identify respective factors for economic success (SHG), self-reliance success (SHG), and social success (ICG, CG).

\subsection{Economic Success in Self-Harvesting Gardens}

In the first step, necessary and sufficient conditions for economic success in the sense of a regular income for the provider of a SHG were calculated. For the calculation, three indicators mentioned above were used: fee per annum, previous experience (as a binary variable with (1) experience and (0) no experience) and educational offerings. It seems evident that an annual fee is an essential condition for generating income. Furthermore, previous experience of the provider of a SHG was assumed as also important for the success and, therefore, for generating a regular income. The third indicator, 
educational offerings, was added based on the assumption that people in urban areas are interested not only in receiving vegetables and herbs but also in learning about agriculture. Therefore, the willingness to pay for participating in SHGs should rise with additional educational offerings.

The following formula for an economically successful and unsuccessful SHG could be identified by running a mvQCA. The minimal formula for the outcome economic success (1), without the inclusion of logical remainders (Formula (1)), is:

Fee (1) $\times$ Experience (1) $\times$ Education (0) + Fee (2) $\times$ Experience (1) $\times$ Education (1) -> Outcome (1),

The formula shows that a medium or high fee and experience are necessary conditions for the economic success of an SHG. The formula is relatively complex. Both terms are simple descriptions of the successful cases. A short configuration formula is achieved by including logical remainders. The latter are configurations without representative cases in the sample that are used to reduce the formula and avoid the problem of limited diversity. The reduced formula indicates that in addition to the necessary condition experience (1) that was calculated in Formula (1), educational offerings are conducive to economic success if the fee is at a high level. On the other hand, additional educational offerings combined with a low fee do not lead to economic success.

The same procedure is used for the identification of necessary and sufficient conditions for economic success (0). In the first step, the formula is calculated without logical remainders (Formula (2)) and in the second step, the logical remainders are included for simplification (Figure 2).

Fee $(2) \times$ Education $(0)+$ Fee $(1) \times$ Education $(1)+$ Fee $(0) \times$ Experience $(0) \times$ Education $(1)->$ Outcome $(0)$,

Two sufficient conditions for outcome (0) can be identified based on the results of the short configuration formula. A SHG does not assure a regular income if no fee is charged and no previous experience is given. In addition, a medium fee and educational offerings or a high fee without educational offerings also lead to no regular income. These results seem to confirm our previous assumptions.

In the second step, the concentration is on the success factors from the point of view of the participating consumers. Self-reliance in food is used as an indicator for success. In this case, food self-reliance success means that participants of SHGs can cover their demand for vegetables and herbs during the season. Three indicators were used for the calculation: the distance the participants traveled to take part in the initiative, the experience of the provider and the possibility of self-organization in the decision-making process, as mentioned above.

The mvQCA shows the formulas for successful SHGs (Formula (3)) and non-successful SHGs in the sense of providing the demand for vegetables and herbs during the season (Formula (4)) without logical remainders. The results including logical reminders can be found in Figure 2.

$$
\begin{gathered}
\text { Experience }(1) \times \text { Distance }(1) \times \text { Participation }(0)+\text { Experience }(2) \times \text { Distance }(1) \\
\times \text { Participation }(0)+\text { Experience }(2) \times \text { Distance }(0) \times \text { Participation }(0)->\text { Outcome }(1), \\
\text { Experience }(1) \times \text { Distance }(2) \times \text { Participation }(0)+\text { Experience }(0) \times \text { Distance }(0) \\
\times \text { Participation }(1)+\text { Experience }(2) \times \text { Distance }(1) \times \text { Participation }(1)+\text { Experience }(0) \\
\times \text { Distance }(2) \times \text { Participation }(0)+\text { Experience }(0) \times \text { Distance }(1) \\
\times \text { Participation }(1)->\text { Outcome }(0)
\end{gathered}
$$

The results for the successful initiatives indicate three necessary conditions: a medium or high previous experience of the provider, a short or medium distance the participants must travel, and no involvement in the decision-making process of the participants. The results of Formula (3), including logical remainders, are reduced to a short or medium distance of travel in combination with the lack of participation (Figure 1). The need for experience disappears because some SHGs cannot cover the demand of the participants in spite of the medium or high previous experience. 


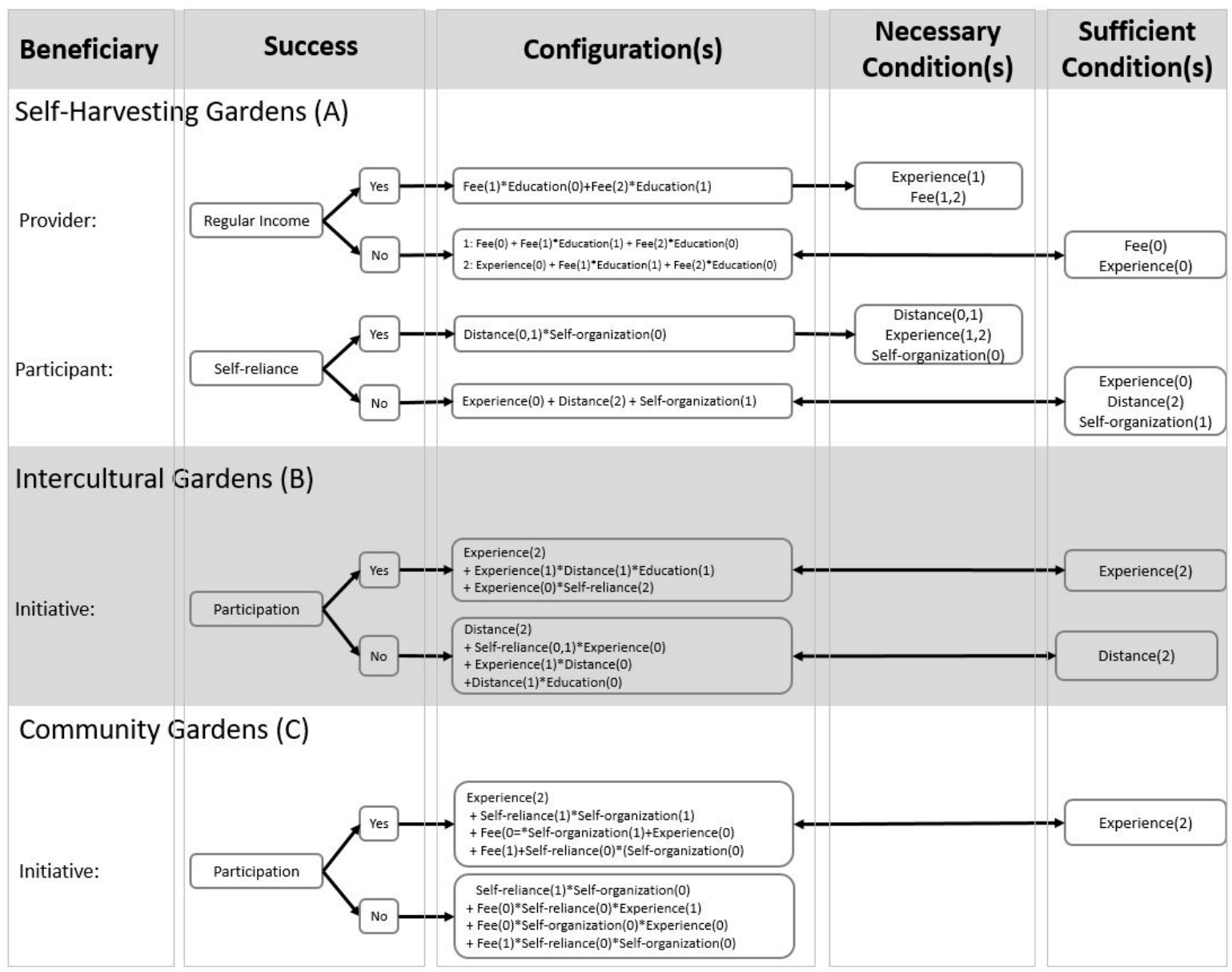

Figure 2. Configurations with logical reminders for SHGs (A), ICGs (B) and CGs (C), including necessary conditions $(\mathbf{A})$ and sufficient conditions $(\mathbf{A}-\mathbf{C})$.

Formula (4) shows the minimal formula for outcome (0), without the inclusion of logical remainders. A shorter version is achieved by rerunning the mvQCA minimization procedure for outcome (0) with the inclusion of logical remainders (Figure 2). Formula (4) only shows simple descriptions, while the reduced formula offers a distinct view. Three sufficient conditions can be identified for unsuccessful SHGs in the sense of food self-reliance for the participants. Each condition-no experience, a long travel distance and self-organization in decision-making processesleads directly to an outcome of (0). In conclusion, self-organization and the distance the participants must travel have a strong influence on the coverage of participants' demand for vegetables and herbs.

Reflecting on the results, SHG can be seen as a business model to generate farm income, as consumers show a willingness to pay for this service. It is remarkable that the expectation of educational offers of high quality, such as workshops or individual advice on gardening practices, is obviously directly related to the willingness to pay a high fee. Initiatives offering education for a low fee, by contrast, fail in economic performance. The additional efforts of the farmer as a trainer are accordingly necessary and fully accepted as a service subject to a fee. A free advisory service can be assumed to be found in practice too, but under certain self-exploitation conditions that are deliberately agreed upon from the farmers' side.

The economic self-reliance motivation of consumers in SHG also indicates implicit cost-benefit considerations. The SHG consumers can expect substantial yields due to the confidence in the professional farmers' experience. Therefore, they are willing to pay in the form of time or money to commute to the garden over medium to long distances. At the same time, any self-government by the 
consumer is refused, which represents a specific and important feature in the business relationship between farmer and SHG members.

\subsection{Social Success in Intercultural and Community Gardens}

While SHGs have a strong economic orientation, ICGs concentrate more on social interconnections and cultural learning between the participants. Therefore, the participation in regular meetings of the initiative seem to be an appropriate indicator for social success. Most of the ICGs are successful in at least at motivating more than half of the participants (57\%) to appear at the meetings (Figure 1). Educational offerings, self-reliance, experience, and distance traveled were chosen as configurations for social success.

Only the formulas including logical remainders that can be found in Figure 2 are reported, because the formulas for successful and unsuccessful became confusing without any additional findings. The results show that a sufficient condition for participation success in ICGs can be found in the high experience of the providers and participants. A medium level of experience coupled with a medium distance traveled and educational offerings, and a missing experience combined with a high level of self-reliance also lead to a successful ICG. By contrast, failure in participation can be expected when the participants have a long travel distance to overcome. In addition, a low production output when spatial proximity meets low experience, or when no educational benefits are gained, while traveling a medium distance lead to unsuccessful initiatives (Figure 2).

Similar to ICGs, CGs concentrate on social issues. Therefore, the motivation of participants to join the regular meetings can be seen as an indicator of a successful initiative. Nevertheless, some different variables were used for the configuration. While self-reliance and experience seem to be important issues for both ICGs and CGs, education and travel distance are less important. Therefore, the fee per annum and the self-organization of the participants were included as significant variables for the determination of social success.

The reduced formulas, including logical remainders of the configuration for successful and unsuccessful initiatives, can be found in Figure 2. A high experience as a sufficient condition for successful CGs was found similar to ICGs. Necessary conditions for participation success in CGs are comparably complex. Self-organization and self-reliance, and the absence of a fee combined with no experience but with self-organization can lead to social success. An initiative can be successful even with failing self-reliance and no self-organization when there is an annual fee. The configurations for unsuccessful initiatives are even more complex. Figure 2 shows various configurations for different forms of initiatives, but it is not possible to calculate a necessary or sufficient condition.

Reflecting on these results, it can be seen that the success factors that ensure maintenance of participation in ICGs and CGs are more complex. Our findings indicate a slightly clearer pattern of trade-off considerations in ICGs than in CGs. Participants in successful ICG initiatives even make efforts regarding commuting, but only in the case of guaranteed considerable self-supply and when there is a willingness to share and gain new experience and education between participants. Too much trial and error, due to low experience, low cultivation efforts, or low common advice, by contrast, make a failure of continuity in participation in an ICG probable. Here, members want to deepen their gardening experiences and take the harvested products home. By contrast, self-reliance is not decisive for the participation success in CGs. A certain shared value culture is indicated through the willingness to bring in and gain experiences and become active in self-government; this is more beneficial the more cost avoidance is realized.

Accordingly, new consumer models seem to go beyond traditional trade-off considerations as production costs and benefit considerations are rather secondary and as leisure activities are also an important motivation. What appear as costs in a productivist concept (e.g., labor costs) seem to be turned into benefits in a post-productive concept (e.g., health effects through green gym).

A differentiation between the consumers participating in SHGs or CSAs and the farmers is very important here. Farmers, who established these forms as a business strategy for multifunctionality 
or diversification, put great emphasis on service orientation, for example, in the knowledge-sharing activities. It would be interesting to know how far farmers follow prevalent business models and perceive these activities more as costs or whether value-sharing models can be identified, similar to what was presumed to be tendentially observed in this study for the consumers' side.

More research is required to substantiate these findings and explore upscaling potentials. Such research might follow the example of the development of organic farming as multifunctional land use integrating post-productive perceptions, which have finally justified the considerable public and policy support and its establishment as an agricultural business model. Nevertheless, it can be observed that in many cities, due to the anticipated positive externalities, different forms of UA receive indirect public support through temporary land access and use rights or through offering public market space to UA associations or communities for sharing or selling their products [21].

To the best of our knowledge, this is the first study providing insights into the conditions of economic viability in UA that takes into consideration the multiple, complex, and UA type-specific success factors and value systems of initiatives. Attempts to quantify the economic performance of UA are as rare as preliminary, because, in contrast to professional agriculture, no data are collected and monitored in UA according to its purposefully non-professional and often leisure activity orientation. Indeed, UA actors, especially urban gardeners, have difficulties to make estimations about yield, input of labor, and other production factors; this sets methodological limitations on quantitative economic analysis approaches [21].

\subsection{Implications Associated with Multiple Roles of Actors}

The hybrid character of roles between consumer and producer is a main common feature of UA models, and partially responsible for the growing adoption of the model from both the consumer and producer side, at least in certain socio-economic, spatial, or farm structural settings. Multifunctionality coupled with flexibilization, for example, in duties for the provision and use of production factors, are the key conceptual pillars, making the hybrid models attractive and workable in specific settings. However, the specific models behind the various UA initiatives differ markedly and this study contributes to the question regarding how far UA initiatives can be addressed as business models at all.

The results confirm the expected distinction and while both farmers and consumers in SHGs perceive their hybrid roles in a highly service-focused food production system, ICGs and CGs do this to only a minor degree. The added value from our study for the further business model development of SHGs is the evidence that farmers' investment in high quality, consumer-demand-oriented knowledge transfer formats and skill development training should be treated as a cost factor to be considered in fee levels, and that perhaps the possibility of modular booking of specific training might meet participating consumers' demands for flexible formats and willingness to pay for services.

\subsection{Methodological Implications}

The results of this study show that multiple factors determine the success or failure of a UA initiative and that the trade-off considerations of the participants differ quite markedly between not only various types of UA but also between initiatives of the same type. Motives and related objectives of participation in a UA initiative are complex, as is known from literature. Frequently stated factors possessing an economic dimension and relating them to cost avoidance or benefit generation strategies as distinct UA economic models suggested by Glavan et al. [21] were chosen for the empirical study. The observation (Figure 1) that cost avoidance factors were found more frequently than benefit generation factors on average across UA models can be interpreted as a first indication that UA models position themselves beyond classical production theory-based considerations. Instead of contrasting input costs to harvested produce value, different input and output factors are important and form trade-off considerations for participation. Herewith, direct and indirect cost avoidance, shown through the participants' decision sphere or UA model inherent, were found. Avoidance 
of commuting costs/time (factor distance) is, for example, a direct cost factor in the participants' decision sphere. It is comparably present like experience and education, both rather indirect factors, safeguarding a certain production success (respectively reducing the risk of complete yield failure), where experience is expected to be shared informally, and education to be offered in a more formalized way, as part of the "business model". The latter, for example, implies that participants follow the same considerations known from farmers participating in training courses ("it pays"), but due to the hybrid role of participants as "prosumers", the leisure aspect ("it's fun") also counts. The combination and frequency distribution of the factors in descriptive analysis already shows the conceptual differences between UA models, but it was necessary to apply an appropriate method, which was found in the QCA, to get better insights into the success of factor mixes.

The QCA was chosen as a method based on the research question and the limited amount of initiatives available. The method is specially made for small and medium sample sizes and is suitable for finding necessary and sufficient conditions for success. Nevertheless, the method also implies some limitations that should be considered. Since the method is based on Boolean logic and configurations, it cannot be assured that there is no case that shows a different result with the same configuration. Therefore, it is only possible to rely on the face validity and on the validity of the construct based on literature. The complexity of the initiatives is very high, as could be seen especially for CGs. This kind of complexity raises the probability that the results might change with a higher response rate. However, based on the theoretical models that could be found in the international discussions on UA, there is no evidence that the results might be biased.

\section{Conclusions}

Despite rapidly growing public, political, and scientific attention, urban agriculture gains have been neglected in research due to its multiple directly and indirectly provided benefits to sustainable urban development, socio-economic viability, and its perception on an initiative level. This is particularly the case for non-commercially oriented forms of urban agriculture, where the lack of data sets limits to quantitative approaches. In this first empirical study on socio-economic viability perception and success factors regarding different urban agriculture types, a mvQCA that allows the statistical analysis of comparably low numbers of observations in highly complex settings was applied. It was possible to identify factors for success and failure of different business and sharing models. The identification of relevant factors and their combination to determine success or failure gives an indication of different value systems and cost-benefit considerations in various urban agriculture types. The self-harvesting gardens are characterised more by a service-focussed business relationship between farmers and consumers who are interested in knowledge and skills acquisition linked to self-reliance. Consumer participation is essential for the viability of intercultural gardens and community gardens. Self-reliance and sharing components are relevant for intercultural gardens, while community gardens exhibit quite fuzzy and differentiated success and failure factor patterns beyond explicit production output but with a clear sharing and self-governance ambition. It can be concluded that these novel findings underline that there is a distinction, if not a gradient, in the business innovation and transition orientation of urban agriculture. The size of the study is certainly a limitation and the partially given and partially questionable plausibility of the model outputs require further research. In any case, multi-value QCA as a method to deal with the particular problems of small and medium n-sized data can be recommended.

Author Contributions: Conceptualization, T.K. and A.P.; Methodology, T.K.; Software, T.K.; Validation, T.K., A.P. and I.Z.; Writing-Original Draft preparation, T.K., I.Z., and A.P.; Funding acquisition, A.P.

Funding: This research was funded by the Federal Ministry of Education and Research, Germany (BMBF), grant number FKZ 16I1623. The Leibniz Centre for Agricultural Landscape Research (ZALF) further financially supported the work on this article. ZALF is institutionally funded by the Federal Ministry of Food, Agriculture and Consumer Protection (BMELV) and the Ministry for Science, Research and Culture of the State of Brandenburg (MWFK). 
Conflicts of Interest: The authors declare no conflict of interest. The funders had no role in the design of the study, in the collection, analyses or interpretation of data, in the writing of the manuscript, or in the decision to publish the results.

\section{Abbreviations}

$\begin{array}{ll}\text { CG } & \text { Community garden } \\ \text { CSA } & \text { Community supported agriculture } \\ \text { ICG } & \text { Intercultural garden } \\ \text { mvQCA } & \text { Multi-value qualitative comparative analysis } \\ \text { SHG } & \text { Self-harvesting garden } \\ \text { UA } & \text { Urban agriculture }\end{array}$

\section{References}

1. Tregear, A. Progressing knowledge in alternative and local food networks: Critical reflections and a research agenda. J. Rural Stud. 2011, 27, 1-12. [CrossRef]

2. Doernberg, A.; Zasada, I.; Bruszewska, K.; Skoczowkski, B.; Piorr, A. Potentials and limitations of regional organic food supply: A qualitative analysis of two food chain types in the Berlin Metropolitan Region. Sustainability 2016, 8, 1125. [CrossRef]

3. Krikser, T.; Piorr, A.; Berges, R.; Opitz, I. Urban agriculture oriented towards self-supply, social and commercial purpose: A typology. Land 2016, 5, 28. [CrossRef]

4. Taylor, J.R.; Lovell, S.T. Urban home gardens in the Global North: A mixed methods study of ethnic and migrant home gardens in Chicago, IL. Renew. Agric. Food Syst. 2015, 30, 22-32. [CrossRef]

5. Holland, L. Diversity and connections in community gardens: A contribution to local sustainability. Local Environ. 2004, 9, 285-305. [CrossRef]

6. Rosol, M. Public participation in post-Fordist urban green space governance: The case of community gardens in Berlin. Int. J. Urban Reg. Res. 2010, 34, 563. [CrossRef]

7. Opitz, I.; Berges, R.; Piorr, A.; Krikser, T. Contributing to food security in urban areas: Differences between urban agriculture and peri-urban agriculture in the Global North. Agric. Hum. Values 2016, 33, 341-358. [CrossRef]

8. Vogl, C.R.; Axmann, P.; Vogl-Lukasser, B. Urban organic farming in Austria with the concept of Selbsternte ('self-harvest'): An agronomic and socio-economic analysis. Renew. Agric. Food Syst. 2004, 19, 67-79. [CrossRef]

9. Lang, K.B. The changing face of community-supported agriculture. Cult. Agric. 2010, 32, 17-26. [CrossRef]

10. Butler Flora, C.; Bregendal, C. Collaborative community supported agriculture: Balancing community capitals for producers and consumers. Int. J. Sociol. Agric. Food 2012, 19, 329-346.

11. Born, B.; Purcell, M. Avoiding the local trap: Scale and food systems in planning research. J. Plan. Educ. Res. 2006, 26, 195-207. [CrossRef]

12. Okvat, H.A.; Zautra, A.J. Community gardening: A parsimonious path to individual, community, and environmental resilience. Am. J. Community Psychol. 2011, 47, 374-387. [CrossRef]

13. Hinrichs, C. The practice and politics of food system localization. J. Rural Stud. 2003, 19, 33-45. [CrossRef]

14. Pole, A.; Gray, M. Farming alone? What's up with the "C" in community supported agriculture. Agric. Hum. Values 2013, 30, 85-100. [CrossRef]

15. Piorr, A.; Zasada, I.; Doernberg, A.; Zoll, F.; Ramme, W. Research for AGRI Committee-Urban and Peri-Urban Agriculture in the EU; European Union: Brussels, Belgium, 2018. [CrossRef]

16. FAO. Profitability and Sustainability of Urban and Peri-Urban Agriculture; Agricultural Management, Marketing and Finance Occasional Paper; Food and Agriculture Organization of the United Nations: Rome, Italy, 2007.

17. Zasada, I. Multifunctional peri-urban areas-A review of societal demands and agricultural provision of goods and services. Land Use Policy 2011, 28, 639-648. [CrossRef]

18. DuPuis, E.M.; Goodman, D. Should we go home to eat? Toward a reflexive politics of localism. J. Rural Stud. 2005, 21, 359-371. [CrossRef] 
19. Bertazzoli, A.; Ruggeri, A.; Samoggia, A. Short Supply Chain: Analysis of the Competitiveness of Organic Horticultural Farmers at Italian Regional Level. In Proceedings of the 118th European Association of Agricultural Economists Seminar, Ljubljana, Slovenia, 25-27 August 2010.

20. Mok, H.-F.; Williamson, V.G.; Grove, J.R.; Burry, K.; Barker, S.F.; Hamilton, A.J. Strawberry fields forever? Urban agriculture in developed countries: A review. Agron. Sustain. Dev. 2014, 34, 21-43. [CrossRef]

21. Glavan, M.; Istenič, M.Č.; Cvejić, R.; Pintar, M. Urban Gardening: From Cost Avoidance to Profit Making —Example from Ljubljana, Slovenia. In Urban Agriculture; Samer, M., Ed.; Intech: London, UK, 2016. [CrossRef]

22. Bohn, K.; Viljoen, A. The edible city: Envisioning the continuous productive urban landscape. Field J. 2011, 4, 149-161.

23. Sanyé-Mengual, E.; Orsini, F.; Oliver-Solà, J.; Rieradevall, J.; Montero, J.I.; Gianquinto, G. Techniques and crops for efficient rooftop gardens in Bologna, Italy. Agron. Sustain. Dev. 2015, 35, 1477-1488. [CrossRef]

24. Opitz, I.; Specht, K.; Piorr, A.; Siebert, R.; Zasada, I. Effects of consumer-producer interactions in alternative food networks on sonsumers' learning about food and agriculture. Morav. Geogr. Rep. 2017, 25, 181-191. [CrossRef]

25. Wiskerke, J.S.C. On places lost and places regained: Reflections on the alternative food geography and sustainable regional development. Int. Plan. Stud. 2009, 14, 369-387. [CrossRef]

26. Langellotto, G.; Melathopoulos, A.; Messer, I.; Anderson, A.; McClintock, N.; Costner, L. Garden pollinators and the potential for ecosystem service flow to urban and peri-urban agriculture. Sustainability 2018, 10, 2047. [CrossRef]

27. Sanyé-Mengual, E.; Orsini, F.; Gianquinto, G. Revisiting the sustainability concept of urban food production from a stakeholders' perspective. Sustainability 2018, 10, 2175. [CrossRef]

28. Oberholtzer, L.; Clancy, K.; Esseks, J.D. The future of farming on the urban edge: Insights from 15 U.S. counties about farmland protection and farm viability. J. Agric. Food Syst. Community Dev. 2016, 1, 59-75. [CrossRef]

29. Scharf, N.; Wachtel, T.; Reddy, S.; Säumel, I. Urban commons for the edible city-First insights for future sustainable urban food systems from Berlin, Germany. Sustainability 2019, 11, 966. [CrossRef]

30. Lohrberg, F.; Lička, L.; Scazzosi, L. Urban Agriculture Europe; JOVIS Publishers: Berlin, Germany, 2016.

31. Dimitri, C.; Oberholtzer, L.; Pressman, A. Urban agriculture: Connecting producers with consumers. Br. Food J. 2016, 118, 603-617. [CrossRef]

32. Bruynis, C.; Goldsmith, P.D.; Hahn, D.E.; Taylor, W.J. Critical success factors for emerging agricultural marketing cooperatives. J. Coop. 2001, 16, 14-24.

33. Ajayi, A.O. An assessment of farmers' willingness to pay for extension services using the contingent valuation method (CVM): The case of Oyo State, Nigeria. J. Agric. Educ. Ext. 2006, 12, 97-108. [CrossRef]

34. Budak, D.B.; Budak, F.; Kaçira, O.O. Livestock producers' needs and willingness to pay for extension services in Adana Province of Turkey. Afr. J. Agric. Res. 2010, 5, 1187-1190. [CrossRef]

35. Cronqvist, L.; Berg-Schlosser, D. Multi-Value QCA (mvQCA). In Configurational Comparative Methods Qualitative Comparative Analysis (QCA) and Related Techniques; Rihoux, B., Ragin, C.C., Eds.; Sage: Newcastle upon Tyne, UK, 2009; pp. 69-86.

(C) 2019 by the authors. Licensee MDPI, Basel, Switzerland. This article is an open access article distributed under the terms and conditions of the Creative Commons Attribution (CC BY) license (http://creativecommons.org/licenses/by/4.0/). 